\title{
Diagnostic potential of nested PCR, galactomannan EIA, and Beta-D-glucan for invasive aspergillosis in pediatric patients
}

\author{
Parisa Badiee ${ }^{1}$, Abdolvahab Alborzi ${ }^{1}$, Mahammad Karimi ${ }^{1}$, Bahman Pourabbas ${ }^{1}$, Pedram Haddadi ${ }^{2}$, Jalal \\ Mardaneh $^{3}$, Mahsa Moieni ${ }^{1}$ \\ ${ }^{1}$ Prof. Alborzi Clinical Microbiology Research Center, ${ }^{2}$ Student Research Committee, Shiraz University of Medical \\ Sciences, Shiraz, Iran \\ ${ }^{3}$ Department of Pathobiology, School of Public Health and Institute of Public Health Research, Tehran University of \\ Medical Sciences, Tehran, Iran
}

\begin{abstract}
Introduction: Limited specific data and investigations are available for invasive aspergillosis (IA) in pediatric patients. We evaluated the diagnostic potential of three noninvasive tests including the Platelia Aspergillus EIA kit for using galactomannan antigen, $(1,3)-\beta-D-$ glucan Detection Reagent Kit, and nested-PCR for Aspergillus DNA in sera. We evaluated the diagnostic potential of three noninvasive tests including EIA for galactomannan antigen (Platelia Aspergillus), nested PCR assay for Aspergillus DNA and test for (1 $\rightarrow 3$ )- $\beta$-D-glucan (Glucatell assay Kit).

Methodology: All pediatric patients treated at the hematology/oncology unit who were at increased risk of developing invasive aspergillosis were enrolled. Clinical samples were examined for Aspergillus infections by mycological methods. Serial blood samples were collected twice weekly and evaluated by noninvasive tests.

Results: We analyzed 230 consecutive blood samples from 62 pediatric patients. The incidence rate of invasive aspergillosis in the patients was found to be $27.4 \%$, and the etiologic agents were Aspergillus flavus, Aspergillus fumigatus, and Aspergillus spp. The sensitivity, specificity, positive and negative predictive values, and likelihood ratios for positive and negative results of galactomannan in patients with proven and probable IA were $90 \%, 92 \%, 81.8 \%, 96 \%, 11.25$, and 0.1 ; for beta-D-glucan they were $50 \%, 46 \%, 26 \%, 70.6 \%, 0.9,0.9$; and for nested-PCR they were $80 \%, 96.2 \%, 88.9 \%, 92.6 \%, 21$, and 0.2 , respectively.

Conclusions: The conventional methods are not able to detect IA, due to the lack of valid and proper sampling. Galactomannan and nestedPCR tests in serum, with enough accuracy and reliability, can serve as noninvasive methods for the detection of IA in pediatric patients. However, the beta-D-glucan test cannot serve as an efficient diagnostic tool in those with hematologic disorders.
\end{abstract}

Key words: galactomannan; D-glucan; nested-PCR, hematologic disorder; aspergillosis

J Infect Dev Ctries 2012; 6(4):352-357.

(Received 31 May 2011 - Accepted 21 November 2011)

Copyright (C) 2012 Badiee et al. This is an open-access article distributed under the Creative Commons Attribution License, which permits unrestricted use, distribution, and reproduction in any medium, provided the original work is properly cited.

\section{Introduction}

Pediatric patients with cancer, particularly those with hematologic malignancies, are at increased risk of developing invasive aspergillosis (IA), which is a major cause of morbidity and mortality in immunosuppressed patients. Documented IA with a death rate of $80-90 \%$ is difficult to treat $[1,2]$. In two large series of studies, the most common underlying condition for IA was malignancy $(74 \%$ and $63 \%)$, with the case fatality of $53 \%[3,4]$.

The diagnosis of IA is difficult and early diagnosis and initiation of antifungal therapy is important to achieve the best outcome. Using traditional mycological methods (microscopy and culture) for analyzing clinical samples is time-consuming. Furthermore, obtaining representative sample material using invasive procedures may be difficult in pediatric settings, and blood culture is not useful for the detection of Aspergillus (A) spp $[5,6]$.

Significant recent advances have been made in the ability to more rapidly identify fungal infections, such as Aspergillus galactomannan, $(1 \rightarrow 3)-\beta$-D-glucan (BDG) and molecular assays. Galactomannan (GM) is a cell-wall polysaccharide component that is released by Aspergillus species during growth and can be detected in patients with aspergillosis. BDG, a cell wall component of many fungi, activates factor $G$ of the horseshoe crab coagulation cascade, causing activation of a chromogenic substrate in an assay [7]. BDG is found in most fungi, including Aspergillus and Candida. When compared to the GM antigenemia test, the sensitivity was $55 \%$ in the BDG test versus $100 \%$ 
for the GM enzyme immunoassay EIA [8]. Few studies have reported on the BDG test in the pediatric population. Several PCR assays to detect Aspergillus DNA have been established $[9,10]$, but few studies have been conducted on the molecular tools for the diagnosis of IA in children.

In the present study, we evaluated the diagnostic potential of three noninvasive tests for IA, including the Platelia Aspergillus EIA for GM antigen, Glucatell assay for $\mathrm{BDG}$ and the polymerase chain reaction (nested PCR) assay for Aspergillus DNA in the sera of the pediatric patients.

\section{Methodology}

This study, which was conducted between November 2008 and November 2009, included all the pediatric patients (1-14 years old) with hematology disorders who were treated at the hematology/oncology unit of Faghihi Hospital, Shiraz University of Medical Sciences, Iran. All study participants were identified as being at increased risk of developing IA. In febrile patients, the first choice of antibiotics used were beta lactam and aminoglycosides, but after three days if they did not respond to these antibiotics and fever persisted, or according to microbiologic results, the antibiotic was changed, or vancomycin therapy was initiated. The patients did not receive any antifungal prophylaxis. They were examined for signs of fungal infections twice weekly and clinical samples (88 samples including sputum, abdominal tap, cerebrospinal fluid, pleural, broncho alveolar lavage or bronchial washing, and biopsy) from those with positive signs were tested for Aspergillus infections by mycological methods, culture on Sabouraud dextrose agar (Merck, Darmstadt, Germany), and direct microscopic examination. Blood samples $(5 \mathrm{ml})$ were cultured by bedside inoculation to BACTEC medium (BectonDickinson, Sparks, MD, USA). Radiologic studies such as chest $\mathrm{X}$ ray, sonography, and computed tomography from each body site were performed in patients with clinical signs and symptoms of the disease. Serial blood samples were collected twice weekly and evaluated for Aspergillus DNA, GM and BDG circulating antigens.

Detection of Aspergillus GM was performed using the Platelia Aspergillus EIA (immunoenzymatic sandwich microplate assay, Bio-Rad, Platelia, Marnes La Coquette, France), according to the manufacturer's protocol. GM assay index $\geq 0.5$ was considered positive. BDG was measured with the Glucatell assay kit Cape Cod East Falmouth, MA, USA), according to the manufacturer's instructions. Concentrations greater than $80 \mathrm{pg} / \mathrm{ml}$ were considered positive.

Fungal DNA was extracted using the QIAmp DNA minikit (Qiagen, Hilden, Germany), in accordance with the manufacturer's recommendations from the sera. Procedures described by Yamakami et al. were used for the nested PCR [11], with two sets of primers universal for all the Aspergillus species. Suspensions of blood with Aspergillus (A. flavus, A. niger and A. fumigatus) conidia ( 1 to $10^{5}$ conidia/ $\mathrm{ml}$ ) were used to determine the limit of the assay, and each solution was used for DNA extraction and PCR. All primers were synthesized by TIB-MOLBIOL (Berlin, Germany). Classification of patients was performed according to the protocols of the European Organization for Research and Treatment of Cancer-Mycosis Study Group [12]. Accordingly, the reference gold standards (positive culture from clinical samples) used to calculate the specificity and sensitivity were the mycological criteria (without indirect tests including GM and BDG) along with host factors, and clinical criteria. Sera from 20 healthy volunteers served as negative controls in all the tests. Data were entered into SPSS version 16 (IBM SPSS, Chicago, USA).

\section{Ethical considerations}

The ethics committee of the Clinical Microbiology Research Center, Shiraz University of Medical Sciences, reviewed and approved the study. All patients' written informed consent was obtained prior to the study.

\section{Results}

We analyzed 230 consecutive (mean: 4 samples per patients) blood samples from 62 pediatric patients with hematological disorders, who were at risk for IA. The mean age of the patients was 9.3 years. The patients consisted of those undergoing induction therapy of acute lymphocytic leukemia (29 cases, $46.8 \%$ ), followed by acute myelocytic leukemia (12 cases, 19.4\%), and other patients (21 cases, 33.8\%) with aplastic anemia, pancytopenia, chronic myelocytic leukemia, and chronic lymphocytic leukemia. Thirty-seven patients had neutropenia < $500 / \mathrm{L}$ for more than 10 days.

In total, there were 36 patients (with respective 129 blood samples) whose clinical, radiological or mycological signs indicated suspicion for IA. Also, there were 26 patients with the same background (101 blood samples) without any signs and symptoms who were accepted as controls. The suspected patients, according to EORTC/MSC criteria, were classified as 
Table 1. Characteristics of patients with proven and probable Aspergillus infections

\begin{tabular}{|c|c|c|c|c|c|c|c|c|c|c|}
\hline Name & $\begin{array}{l}\text { Age/ } \\
\text { sex }\end{array}$ & $\begin{array}{c}\text { Back } \\
\text { ground }\end{array}$ & $\begin{array}{c}\text { PCR } \\
\text { result }\end{array}$ & $\begin{array}{c}\text { Mean } \\
\text { GM }\end{array}$ & $\begin{array}{l}\text { Mean } \\
\text { BDG }\end{array}$ & $\begin{array}{c}\text { Method of } \\
\text { diagnosis }\end{array}$ & Culture & $\begin{array}{c}\text { Site Infection/ } \\
\text { Specimen }\end{array}$ & $\begin{array}{c}\text { IA } \\
\text { group }\end{array}$ & Outcome \\
\hline 1 & $\mathrm{~F} / 14$ & AML & + & 0.545 & 65 & Clinical/radiology & A. flavus & $\begin{array}{c}\text { Lung/ } \\
\text { Bronchial } \\
\text { washing }\end{array}$ & Probable & Died \\
\hline 2 & $\mathrm{~F} / 7$ & AML & + & 0.530 & 192 & Clinical/radiology & $\begin{array}{c}A . \\
\text { fumigatus }\end{array}$ & $\begin{array}{c}\text { Lung/ } \\
\text { Bronchial } \\
\text { washing } \\
\end{array}$ & Probable & Died \\
\hline 3 & $\mathrm{M} / 5$ & AML & + & 0.915 & 95 & Clinical/radiology & A. flavus & $\begin{array}{c}\text { Lung/ } \\
\text { Bronchial } \\
\text { washing }\end{array}$ & Probable & Survived \\
\hline 4 & $\mathrm{~F} / 8$ & ALL & - & - & - & Clinical/radiology & $\begin{array}{c}A . \\
\text { fumigatus } \\
\end{array}$ & $\begin{array}{c}\text { Sinus/Sinus } \\
\text { washing }\end{array}$ & Probable & Survived \\
\hline 5 & $\mathrm{~F} / 5$ & ALL & + & 0.500 & 112 & Biopsy/radiology & A. flavus & Sinus/ Biopsy & Proven & Survived \\
\hline 6 & $\mathrm{M} / 11$ & AML & + & 1.154 & 110 & Clinical/radiology & A. spp. & $\begin{array}{c}\text { Lung/ } \\
\text { Bronchial } \\
\text { washing }\end{array}$ & Probable & Died \\
\hline 7 & $\mathrm{M} / 11$ & NHL & + & 0.61 & 74 & Clinical/radiology & A. flavus & $\begin{array}{c}\text { Lung/ } \\
\text { Bronchial } \\
\text { washing } \\
\end{array}$ & Probable & Survived \\
\hline 8 & $\mathrm{M} / 14$ & ALL & - & 0.598 & 125 & Clinical/radiology & $\begin{array}{c}\text { A. } \\
\text { fumigatus }\end{array}$ & $\begin{array}{c}\text { Lung/ } \\
\text { Bronchial } \\
\text { washing } \\
\end{array}$ & Probable & Died \\
\hline 9 & $\mathrm{M} / 3$ & ALL & + & 1.79 & 72 & Clinical/radiology & $\begin{array}{c}A . \\
\text { fumigatus }\end{array}$ & $\begin{array}{c}\text { Lung/ } \\
\text { Bronchial } \\
\text { washing }\end{array}$ & Probable & Survived \\
\hline 10 & $\mathrm{~F} / 14$ & ALL & + & 0.841 & 55 & Clinical/radiology & $\begin{array}{c}A . \\
\text { fumigatus }\end{array}$ & $\begin{array}{c}\text { Lung/ } \\
\text { Bronchial } \\
\text { washing }\end{array}$ & Probable & Survived \\
\hline
\end{tabular}

F: Female, M: Male, AML, Acute Myelocytic leukemia, ALL: Acute Lymphocytic Leukemia, NHL: Non Hodgkin Lymphoma, A: Aspergillus

follows: 1 proven and 9 probable (Aspergillus spp. was isolated from clinical samples of these patients by mycological methods) and 26 possible. Twenty-six sputums, 2 abdominal fluids, 5 cerebrospinal fluids, 2 pleural fluid, 48 broncho alveolar lavages, and 5 sinus biopsies were examined and Aspergillus spp. was isolated from 10 clinical samples. The etiologic agents were four cases of A. flavus, five cases of A. fumigatus, and one case of Aspergillus spp. None of the patients with IA had positive blood culture result. In possible cases $(\mathrm{N}=26)$, these methods were not able to help the clinicians with diagnosis. Characteristics of the patients with proven and probable Aspergillus infections are presented in Table 1.

GM antigen test was positive in 9 patients (28 out of 38 blood samples) with proven and probable aspergillosis, and in 3 possible cases (8 out of 15 blood samples), according to EORTC/MSG criteria, in serial samples. There was one probable patient with a negative GM test and in 2 of the 26 patients ( 5 out of 101 samples) with no clinical or mycological evidence of IA, the GM antigen test was positive. Therefore, the sensitivity, specificity, positive and negative predictive values, and likelihood ratio for a positive and negative result of the GM EIA method in patients with proven and probable IA were $90 \%, 92 \%, 81.8 \%, 96 \%, 11.25$ and 0.1 , respectively. The results of the GM EIA test in all the healthy volunteers were negative.

BDG test results were positive in 5 pediatric patients (18 out of 22 samples) with proven and probable criteria, in 11 possible cases (35 out of 40 samples), and in 14 patients with no criteria of IA (30 out of 101 samples). The sensitivity, specificity, positive and negative predictive value, and likelihood ratios for positive and negative result values of these methods in patients with proven and probable disease were $50 \%, 46 \%, 26 \%, 70.6 \%, 0.9$, and 0.9 , respectively.

The lowest limit for nested-PCR was $1 \mathrm{cfu} / \mathrm{ml}$. Nested-PCR was positive in different samples of 8 proven and probable patients (31 out of 33 samples), and 7 possible cases (25 out of 29 blood samples). There were two patients with IA, according to EORTC/MSG criteria and negative PCR results. One 
patient without clinical signs was positive with nested -PCR (2 blood samples). The sensitivity, specificity, negative and positive predictive values, and likelihood ratio for positive and negative result of the nested-PCR in pediatric patients with proven and probable IA were, $80 \%, 96.2 \%, 88.9 \%, 92.6 \%, 21$, and 0.2 , respectively. None of the tests was positive in the 20 healthy volunteer negative controls.

According to clinical standard protocols, antifungal therapy was started for the patients with criteria of IA. Seven patients with clinical suspicion of IA and a positive PCR were responsive to antifungal therapy. Therefore, based on the clinical, radiological, and mycological evidence (EORTC/MSG criteria) and response to antifungal agents, the incidence rate of IA in the patients was found to be $27.4 \%$ ( 1 proven, 9 probable, and 7 possible). IA was the most prevalent disorder in patients with acute myelocytic leukemia and the lung was the most infected site of infections, followed by sinusitis. Six patients $(35.3 \%)$ with IA died despite the antifungal therapy they received.

\section{Discussion}

Early detection of IA is critical in pediatric febrile neutropenic patients. Mycological methods (microscopy and culture examination), and isolation of fungal agents in clinical samples are important for IA diagnosis, but blood cultures are negative for the detection of Aspergillus spp. [5,6]. The cultures were positive in proven and probable cases (sensitivity and specificity were $100 \%$ ), but this method cannot help the diagnosis in possible patients for whom clinical sampling such as bronchoalveolar lavage or biopsy is not available, because it is invasive and not feasible in neutropenic patients.

According to the present study, both GM EIA and nested-PCR are able to diagnose IA in pediatric patients; however, the use of latter test is limited due to the increased cost and non- availability in routine diagnostic laboratories in developing countries.

GM cut-off value is an important factor in determining the sensitivity and specificity of the test. GM test is reported as positive when, in 2 aliquots from the same sample, the optical density $\geq 0.5$. The GM index may be different depending on the study population and types of samples; it can be the disadvantage of this method. Some reports, such as that of Herbrecht et al., indicate the lowered cut-off value in different treatments including adults with non-allo-hematopoietic stem cell transplantation [13]. Marr et al. reported that sensitivity was highest $(87.5 \%)$ in patients who did not receive preventive mold-active antifungals [14]. The sensitivity of the galactomannan detection test was reported to be within $50.0 \%$ [15] and 90.6\% [16] in different articles. A recent meta-analysis reported a sensitivity of $79 \%$ and a specificity of $86 \%$, with an overall accuracy of $89 \%$ for the GM test [17]. A limitation of the GM test is the observation of false-positive results as reported in many studies on patients with Aspergillus treated with some antibiotics such as amoxicillin-clavulanate [18], piperacillin-tazobactam, and beta-lactams, even up to five days after the cessation of treatment [19], and also in studies involving patients infected with fungi other than Aspergillus [20]. Nested PCR is able to detect Aspergillus DNA in blood samples from patients with IA, with high sensitivity and specificity rates. The sensitivity and specificity for nested PCR in proven and probable patients in this study were compatible with those of other studies [21]. Sensitivity and specificity rates of the nested PCR assay in Hummel et al.'s study [22] on pediatric patients were $80 \%$ and $81 \%$, respectively.

Direct comparisons between molecular methods and the GM assay for the detection of aspergillosis do not yield consistent results as to which test is best [8, 23]. However, Suarez et al. report that in comparison to GM test, the PCR assay was found to be highly sensitive and specific for the early diagnosis of IA in high-risk patients with hematological disorders [24]. In our study, there were only 10 patients with positive results for IA, in two of whom the nested PCR positive result was obtained earlier than the GM result. Since the number of patients with IA was very limited, further studies are needed to consolidate the present results. Positive likelihood ratios for GM, BDG, and nested-PCR were $11.25,0.9$, and 21 , respectively. The higher the positive likelihood ratio, the better the test; therefore, nested-PCR could be the best method for the diagnosis of IA in febrile neutropenic pediatric patients. Regular screening for GM and DNA could be useful among high-risk pediatric patients for prompt further preemptive antifungal therapy. In all conditions, the GM-EIA and PCR results must be checked with clinical, radiological, and laboratory findings.

BDG, a panfungal cell wall component, has also been developed for the diagnosis of invasive fungal infections. False positive results may be seen for BDG because it is ubiquitous in the environment. Furthermore, some conditions such as exposure to certain gauzes [25], taking several antibiotics at high concentrations [26], using certain hemodialysis cellulose membranes [27], and receipt of albumin or 
immunoglobulin products, plasma proteins or coagulation factors [28] may contribute to a greater yield of false positive. False positives by BDG may also be obtained by a variety of other reasons including "bacteremia, hemolysis; intravenous administration of treatment with certain medications; exposure to cotton bandages; heat stroke; and unknown causes" [29,30]. The use of different species of horseshoe crab as a source of reagent by the manufacturers creates different cutoff values. In this study, all the controls had BDG $<20 \mathrm{pg} / \mathrm{ml}$ while of the patients, only 6 had BDG $<60 \mathrm{pg} / \mathrm{ml}$ and many patients had BDG between $60-100 \mathrm{pg} / \mathrm{ml}$; therefore, $\mathrm{BDG} \geq 80 \mathrm{pg} / \mathrm{ml}$ was considered a positive result. This high value of BDG might be due to the study population, who were febrile pediatric cases. The present results showed that the BDG test is not specific in pediatric febrile neutropenia. Digby et al. also reported that the BDG test is not specific in febrile neutropenia patients admitted to the ICU [30].

In the present study, the sensitivity of BDG was lower than that observed using other methods, which were comparable with other studies such as that by Kawazu M et al. which reported 0.55\% [8], and Senn et al. [31] which reported $63 \%$, on neutropenic episodes.

False positive results in the present study might have been due to the use of some antibacterial agents that can affect GM test results, or chemotherapy which damages the tissues and may lead to transient fungemia.

\section{Summary}

Conventional methods are not able to detect IA, due to the lack of valid and proper sampling. GM and PCR tests in serum, though with differences in sensitivity, specificity, positive and negative predictive values, can serve as noninvasive methods for the detection of IA in pediatric patients. The combination of these two tests can help a rapid diagnosis of IA in neutropenic patients. As demonstrated, the BDG test cannot serve as an efficient diagnostic tool in pediatrics with hematologic disorders.

\section{Acknowledgements}

The authors would like to thank Dr. Hassan Khajea and Dr. Nasrin Shokrpour at the Center for Development of Clinical Research of Nemazee Hospital for editorial assistance.

\section{References}

1. Kim MJ, Lee KS, Kim J, Jung KJ, Lee HG, Kim TS (2001) Crescent sign in invasive pulmonary aspergillosis: frequency and related CT and clinical factors. J Comput Assist Tomogr 25: 305-310.

2. Horger M, Einsele H, Schumacher U, Wehrmann M, Hebart $\mathrm{H}$, Lengerke C, Vonthein R, Claussen CD, Pfannenberg C (2005) Invasive pulmonary aspergillosis: frequency and meaning of the "hypodense sign" on unenhanced CT. Br J Radiol 78: 697-703.

3. Burgos A, Zaoutis TE, Dvorak CC, Hoffman JA, Knapp KM, Nania JJ, Prasad P, Steinbach WJ (2008) Pediatric invasive aspergillosis: a multicenter retrospective analysis of 139 contemporary cases. Pediatrics 121:1286-1294.

4. Zaoutis TE, Heydon K, Chu JH, Walsh TJ, Steinbach WJ (2006) Epidemiology, outcomes, and costs of invasive aspergillosis in immunocompromised children in the United States, 2000. Pediatrics 117: 711-716.

5. Meyer MH, Letscher-Bru V, Jaulhac B, Waller J, Candolfi E (2004) Comparison of Mycosis IC/F and plus Aerobic/F media for diagnosis of fungemia by the bactec 9240 system. J Clin Microbiol 42: 773-777.

6. McDonald LC, Weinstein MP, Fune J, Mirrett S, Reimer LG, Reller LB (2001) Controlled comparison of BacT/ALERT FAN aerobic medium and BATEC fungal blood culture medium for detection of fungemia. J Clin Microbiol 39:622624.

7. Miyazaki T, Kohno S, Mitsutake K, Maesaki S, Tanaka K, Ishikawa N, Hara K 1995 Plasma $(1 \rightarrow 3)-\beta$-D-glucan and fungal antigenemia in patients with candidemia, aspergillosis, and cryptococcosis. J Clin Microbiol 33: 3115-3118.

8. Kawazu M, Kanda Y, Nannya Y, Aoki K, Kurokawa M, Chiba S, Motokura T, Hirai H, Ogawa S (2004) Prospective comparison of the diagnostic potential of real-time PCR, double-sandwich enzyme-linked immunosorbent assay for galactomannan, and a $(1 \rightarrow 3)-\beta-D$-glucan test in weekly screening for invasive aspergillosis in patients with hematological disorders. J Clin Microbiol 42: 2733-2741.

9. Lass-Flörl C, Gunsilius E, Gastl G, Freund M, Dierich MP, Petzer A (2005) Clinical evaluation ofAspergillus-PCR for detection of invasive aspergillosis in immunosuppressed patients. Mycoses 48: 12-17.

10. Badiee P, Alborzi A, Shakiba E, Ziyaeyan M, Pourabbas B (2009) Molecular diagnosis of Aspergillus endocarditis after cardiac surgery. J Med Microbiol 58: 192-195.

11. Yamakami Y, Hashimoto A, Tokimatsu I, Nasu M (1996) PCR detection of DNA specific for Aspergillus species in serum of patients with invasive aspergillosis. J Clin Microbiol 34: 2464-2468.

12. De Pauw B, Walsh TJ, Donnelly JP, Stevens DA, Edwards JE, Calandra T, Pappas PG, Maertens J, Lortholary O, Kauffman CA, Denning DW, Patterson TF, Maschmeyer G, Bille J, Dismukes WE, Herbrecht R, Hope WW, Kibbler CC, Kullberg BJ, Marr KA, Muñoz P, Odds FC, Perfect JR, Restrepo A, Ruhnke M, Segal BH, Sobel JD, Sorrell TC, Viscoli C, Wingard JR, Zaoutis T, Bennett JE; (2008) Revised definitions of invasive fungal disease from the European Organization for Research and Treatment of Cancer/Invasive Fungal Infections Cooperative Group and the National Institute of Allergy and Infectious Diseases Mycoses Study Group [EORTC/MSG] Consensus Group. Clin Infect Dis 46: 1813-1821.

13. Herbrecht R, Letscher-Bru V, Oprea C, Lioure B, Waller J, Campos F, Villard O, Liu KL, Natarajan-Amé S, Lutz P, Dufour P, Bergerat JP, Candolfi E (2002) Aspergillus 
galactomannan detection in the diagnosis of invasive aspergillosis in cancer patients. J Clin Oncol 20: 1898-1906.

14. Marr KA, Balajee SA, McLaughlin L, Tabouret M, Bentsen C, Walsh TJ (2004) Detection of galactomannan antigenemia by enzyme immunoassay for the diagnosis of invasive aspergillosis: variables that affect performance. J Infect Dis 190: 641-649.

15. Pinel C, Fricker-Hidalgo H, Lebeau B, Garban F, Hamidfar R, Ambroise-Thomas P, Grillot R (2003) Detection of circulating Aspergillus fumigatus galactomannan: value and limits of the Platelia test for diagnosing invasive aspergillosis. J Clin Microbiol 41: 2184-2186.

16. Sulahian A, Boutboul F, Ribaud P, Leblanc T, Lacroix C, Derouin F (2001) Value of antigen detection using an enzyme immunoassay in the diagnosis and prediction of invasive aspergillosis in two adult and pediatric hematology units during a 4-year prospective study. Cancer 91: 311-318.

17. Pfeiffer CD, Fine JP, Safdar N (2006) Diagnosis of invasive aspergillosis using a galactomannan assay: a meta-analysis. Clin Infect Dis 42: 1417-1427.

18. Zandijk E, Mewis A, Magerman K, Cartuyvels R (2008) False-positive results by the platelia Aspergillus galactomannan antigen test for patients treated with amoxicillin-clavulanate. Clin Vaccine Immunol 15: 11321133.

19. Aubry A, Porcher R, Bottero J, Touratier S, Leblanc T, Brethon B, Rousselot P, Raffoux E, Menotti J, Derouin F, Ribaud P, Sulahian A (2006) Occurrence and kinetics of false-positive Aspergillus galactomannan test results following treatment with beta-lactam antibiotics in patients with hematological disorders. J Clin Microbiol 44: 389-394.

20. Wheat LJ and Walsh TJ (2008) Diagnosis of invasive aspergillosis by galactomannan antigenemia detection using an enzyme immunoassay. Eur J Clin Microbiol Infect Dis 27: 245-251.

21. Badiee P, Alborzi A, Malekhosseini SA, Nikeghbalian S, Shakiba E (2010) Determining the incidence of aspergillosis after liver transplant. Transplant Experimental and Clinical Transplantation 3: 220-223.

22. Hummel M, Spiess B, Roder J, von Komorowski G, Dürken M, Kentouche K, Laws HJ, Mörz H, Hehlmann R, Buchheidt D (2009) Detection of Aspergillus DNA by a nested PCR assay is able to improve the diagnosis of invasive aspergillosis in paediatric patients. J Med Microbiol 58: 12911297.

23. Ahmad S, Khan ZU, Theyyathel AM (2007) Diagnostic value of DNA, $(1 \rightarrow 3)-\beta$-D-glucan, and galactomannan detection in serum and bronchoalveolar lavage of mice experimentally infected with Aspergillus terreus. Diagn Microbiol Infect Dis 59: 165-171.

24. Suarez F, Lortholary O, Buland S, Rubio MT, Ghez D, Mahé V, Quesne G, Poirée S, Buzyn A, Varet B, Berche P, Bougnoux ME (2008) Detection of circulating Aspergillus fumigatus DNA by real-time PCR assay of large serum volumes improves early diagnosis of invasive aspergillosis in high-risk adult patients under hematologic surveillance. J Clin Microbiol 46: 3772-3777.

25. Nakao A, Yasui M, Kawagoe T, Tamura H, Tanaka S, Takagi H (1997) False-positive endotoxemia derives from gauze glucan after hepatectomy for hepatocellular carcinoma with cirrhosis. Hepatogastroenterology 44: 1413-1418.

26. Marty FM, Lowry CM, Lempitski SJ, Kubiak DW, Finkelman MA, Baden LR (2006) Reactivity of $(1 \rightarrow 3)-\beta$-Dglucan assay with commonly used intravenous antimicrobials. Antimicrob Agents Chemother 50: 3450-3453.

27. Kato A, Takita T, Furuhashi M, Takahashi T, Maruyama Y, Hishida A (2001) Elevation of blood $(1 \rightarrow 3)-\beta$-D-glucan concentrations in hemodialysis patients. Nephron 89: 15-19.

28. Ikemura K, Tanaka H, Yoshioka T, Sugimoto T (1990) Interference in endotoxin and fungal polysaccharide assays from blood products and antimicrobial agents. Rinsho Byori 38: 87-92.

29. Pickering JW, Sant HW, Bowles CA, Roberts WL, Woods GL (2005) Evaluation of a $(1-33)-\beta$-D-glucan assay for diagnosis of invasive fungal infections. J Clin Microbiol 43: 5957-5962.

30. Digby J, Kalbfleisch J, Glenn A, Larsen A, Browder W, Williams D (2003) Serum glucan levels are not specific for presence of fungal infections in intensive care unit patients. Clin Diagn Lab Immunol 10: 882-885.

31. Senn L, Robinson JO, Schmidt S, Knaup M, Asahi N, Satomura S, Matsuura S, Duvoisin B, Bille J, Calandra T, Marchetti O (2008) $1 \rightarrow 3$ - $\beta$-D-glucan antigenemia for early diagnosis of invasive fungal infections in neutropenic patients with acute leukemia. Clin Infect Dis 46:878-885.

\section{Corresponding author}

Parisa Badiee

Prof. Alborzi Clinical Microbiology Research Center

Zand Avenue, Post code 7193711351,

Nemazi Hospital

Shiraz, Iran

Telephone: \#98 7116474304

Fax: \# 987116474303

Email: Badieep@gmail.com

Conflict of interests: No conflict of interests is declared. 